\title{
Aplikasi Pembelajaran Interaktif Augmented Reality Tata Surya Sekolah Dasar Menggunakan Metode Marker Based Tracking
}

\author{
Ismi Naili Qurrotul Aini, Agung Triayudi*, Ira Diana Sholihati \\ Fakultas Teknologi Komunikasi dan Informatika, Informatika, Universitas Nasional, Jakarta, Indonesia \\ Email: 1isminailiqrn@gmail.com, 2,*agungtriayudi@ civitas.unas.ac.id, ${ }^{3}$ iradiana2803@gmail.com \\ ${ }^{*}$ Email Penulis Korespondensi: agungtriayudi@ civitas.unas.ac.id
}

\begin{abstract}
Abstrak-Seiring dengan perkembangan zaman, maka media pembelajaran juga terus berkembang. Dalam mata pelajaran tata surya, biasanya media yang digunakan adalah buku, dimana siswa hanya dapat melihat bentuk 2D. tujuan penelitian ini adalah membangun aplikasi yang dapat membuat sebuah objek 3D disertai dengan penjelasan, sehingga membuat pembelajaran menjadi lebih interaktif dan mudah dipahami menggunakan teknologi Augmented Reality (AR). Pada jurnal-jurnal sebelumnya telah dibuat aplikasi pembelajaran tata surya menggunakan teknologi AR, dan pada penelitian ini akan dikembangkan dengan membuat menu kuis dan true or false untuk mengetahui seberapa jauh siswa mengerti dengan materi yang diajarkan. Untuk memastikan aplikasi berjalan dengan baik, maka dilakukan pengujian gambar, jarak dan sudut marker, fitur-fitur aplikasi, dan kuisioner menggunakan black box. Hasil pengujian marker dapat dibedakan dengan baik, marker dapat di deteksi dengan baik pada jarak 30-90 cm dengan sudut $45^{\circ}-90^{\circ}$, kemudian kuesioner terhadap 10 siswa sekolah dasar terkait aplikasi ini $100 \%$ menyukai aplikasi AR tata surya sebagai media pembelajaran.
\end{abstract}

Kata Kunci: Augmented Reality, Unity 3D, Marker, Tata Surya, Objek 3D

\begin{abstract}
Along with the times, the learning media also continues to grow. In solar system subjects usually, the media is used is books, where students can only see 2D forms. The purpose of this research is to build an application that can create a 3D object accompanied by an explanation, so as to make learning more interactive and easily understood using Augmented Reality (AR) technology. In previous journals, a solar system learning application has been made using AR technology, and this research will be developed by creating a quiz menu and true or false to find out how far students understand the material being taught. To ensure the application runs well, testing images, distance and angle markers, application features, and questionnaires using a black box. Marker test results can be distinguished well, markers can be detected well at a distance of 30-90 cm with an angle of $45^{\circ}-90^{\circ}$, then questionnaires to 10 elementary school students related to this application $100 \%$ like the solar system AR application as a learning medium.
\end{abstract}

Keywords: Augmented Reality, 3D Unity, Marker, Solar System, 3D Objects

\section{PENDAHULUAN}

Teknologi saat ini semakin berkembang seiring dengan berkembangnya kebutuhan manusia agar memudahkan dan dapat menghemat waktu di dalam berbagai bidang. Salah satu teknologi yang saat ini sedang berkembang adalah objek 3 dimensi (3D) karena sudut pandang yang dimiliki lebih luas dari citra dua dimensi (2D) yang hanya memiliki satu sudut pandang saja, sehingga objek 3D juga lebih interaktif dan imajinatif[1].

Pada saat ini media pembelajaran tata surya di sekolah dasar hanya dipelajari dengan menggunakan media buku, gambar 2D atau berupa video dirasa belum cukup efektif untuk dapat menyampaikan materi karena terbatasnya ingatan siswa dan dengan visualisasi 3D membantu mereka mengingat lebih mudah materi yang disampaikan[2], khususnya pada materi yang kompleks seperti tata surya[3]. Menurut[4] diketahui bahwa minat belajar peserta didik berpengaruh terhadap pemahaman konsep peserta didik.

Untuk memperbaiki hal tersebut, maka diperlukan adanya perubahan metode belajar dengan menggunakan teknologi sebagai alat media pembelajaran agar siswa tidak jenuh pada materi yang disampaikan karena keterbatasan alat peraga saat pelajaran berlangsung. Penggunaan teknologi yang dimaksud adalah dengan menggabungkan dunia nyata (objek yang sesungguhnya) dengan dunia digital, tanpa mengubah bentuk objek sesungguhnya tersebut menggunakan teknologi Augmented Reality (AR) berbasis android[5] dengan metode marker based tracking, yaitu menggunakan penanda atau marker dengan bentuk hitam dan putih persegi dengan batas hitam tebal dan latar belakang putih[6].

Teknologi ini akan lebih menarik kemudian dapat digunakan sebagai media pembelajaran yang interaktif sehingga meningkatkan minat belajar pada siswa[1], selain itu dapat membuat lingkungan belajar di mana buku pelajaran dan objek belajar virtual dapat digunakan secara bersamaan[6]. Augmented Reality yang digunakan dalam pendidikan yaitu untuk memperlihatkan objek atau situasi yang tidak dapat terlihat langsung oleh siswa[6].

Pada penelitian jurnal-jurnal sebelumnya [1], [3], dan [7] telah dibuat aplikasi pembelajaran tata surya yang menggunakan augmented Reality dan metode marker based tracking dan dapat menampilkan objek 3D dengan penjelasan, audio, dan craft. Maka dalam penelitian ini akan mengembangkan aplikasi yang sudah ada dengan menambahkan menu kuis yang terdiri dari pilihan ganda dan soal true or false untuk membantu guru mengetahui dana memantau seberapa jauh siswa memahami apa yang telah dipelajari menggunakan aplikasi ini.

Untuk membangun aplikasi tersebut menggunakan SDK Vuforia, software unity 3D, dan blender 3D untuk membuat objek-objek 3D yang nantinya akan di eksport ke dalam unity. 


\section{METODE PENELITIAN}

\subsection{Use Case Diagram}

Berikut adalah use case diagram augmented reality sistem tata surya.

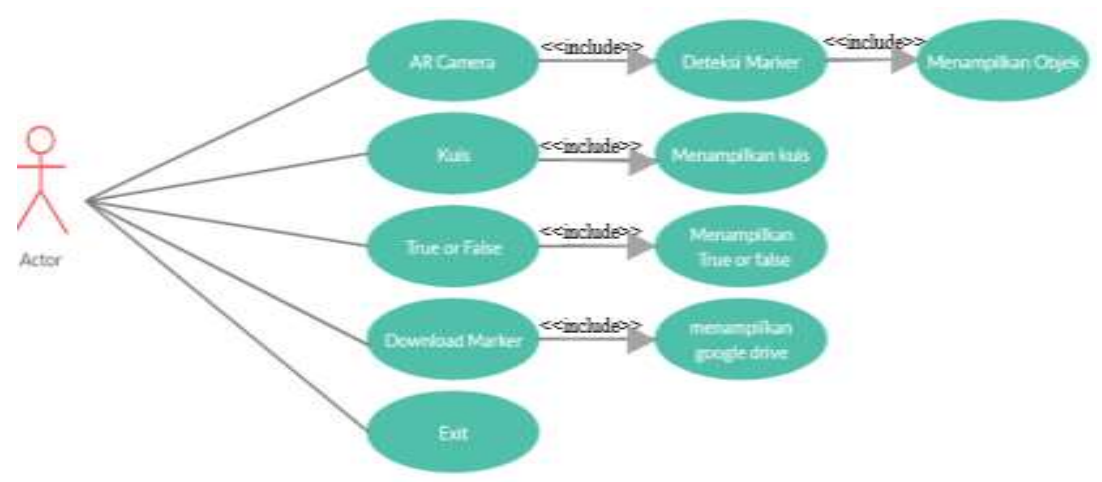

Gambar 1. Use Case Diagram

Pada Gambar 1 adalah use case aplikasi augmented reality tata surya. Saat membuka aplikasi, pengguna akan di hadapkan dengan pilihan menu, yaitu : AR Camera, Kuis, True or false, download marker, dan exit.

a. AR Camera : Setelah menu terbuka, maka scan marker maka objek 3D, penjelesan, dan play sound akan muncul.

b. Kuis : Jika memilih menu ini maka kuis pilihan ganda 4 jawaban akan muncul.

c. True or False: Jika memilih menu ini maka akan menampilkan pertanyaan dengan 2 pilihan jawaban yaitu true dan false.

d. Download marker : Menu ini akan langsung menghubungkan pengguna ke google drive, yaitu tempat menyimpan marker yang dapat di download.

e. Exit : Keluar dari aplikasi

\subsection{Kerangka Penelitian}

Berikut adalah kerangka penelitian sistem tata surya menggunakan augmented reality.

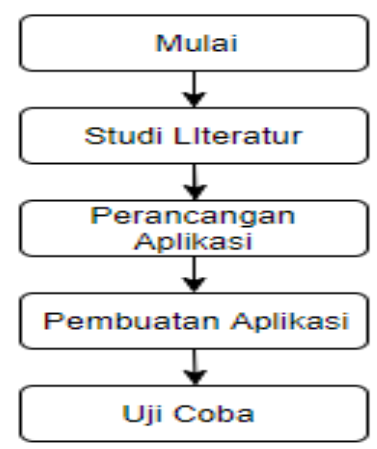

Gambar 2. Kerangka Penelitian

Penelitian ini dimulai dengan mengembangkan media augmented reality untuk pembelejaran materi tata surya. Langkah-langkah yang dilakukan untuk mengembangkan aplikasi ini yaitu: studi pustaka, perancangan aplikasi, pembuatan aplikasi, dan melakukan pengujian seperti pada gambar 2.

Berikut penjelasannya :

a. Studi Literatur, mencari dan mempelajari literatur dari buku, jurnal, serta penelitian sebelumnya yang berkaitan dengan metode marker based tracking augmented reality untuk mengambil kesimpulan berdasarkan hasil pengamatan sebelumnya[8].

b. Perancangan Aplikasi, dalam perancangan aplikasi mencangkup beberapa tahapan, perancangan objek 3D, perancangan User Interface dan perancangan marker.

c. Pembuatan Aplikasi, tahap ini dapat dikerjakan setelah tahapan perancangan sudah selesai menggunakan software unity 3D.

d. Dari rancangan objek dan marker kemudian dibuatlah menjadi sebuah aplikasi pembelajaran tata surya.

e. Uji coba, tahapan pengujian adalah tahapan terakhir, aplikasi di install pada smartphone, untuk melihat apakah semua fitur berjalan dengan baik agar aplikasi dapat digunakan oleh siswa sebagai media pembelajaran. 


\subsection{Unity 3D}

Unity 3D adalah software game engine untuk membangun permainan 3 Dimensi (3D). Pada pengembangan ini, unity digunakan untuk membuat media pembelajaran interaktif 3D dalam pelajaran tata surya. Pengguna unity perlu mengunduh dan memasang sdk Android dan menambahkan perangkat ke fisik sistem.

\subsection{Vuforia SDK}

Vuforia SDK digunakan secara online, barguna untuk memfasilitasi penciptaan atau pengembangan aplikasi mobile Augmented Reality yang memanfaatkan kamera handphone [9]. Vuforia mempunya fitur memindai objek, objek yang dipindai berupa marker tata surya yang telah dibuat.

\subsection{Marker Based Tracking}

Pelacakan berbasis marker menggunakan marker dengan bentuk hitam dan putih dengan batas hitam tebal dan latar belakang putih, atau dengan menggunakan gambar yang mempunyai pola gambar yang unik. Pelacakan ini lebih cocok untuk digunakan pada media kertas daripada metode pelacakan markerless[10]. Marker yang telah dibuat nantinya akan di arahkan ke kamera handphone sebagai media untuk menampilkan objek 3D tata surya.

\section{HASIL DAN PEMBAHASAN}

Pada bagian ini berisi analisa, hasil serta pembahasan dari topik penelitian, yang bisa di buat terlebih dahulu metodologi penelitian. Bagian ini juga merepresentasikan penjelasan yang berupa penjelasan, gambar, tabel dan lainnya.

\subsection{Pembahasan Aplikasi}

Dilakukan pengujian terhadap aplikasi pembelajaran tata surya untuk mengetahui apakah aplikasi sudah dapat dijalankan sesuai yang di rancang atau tidak.

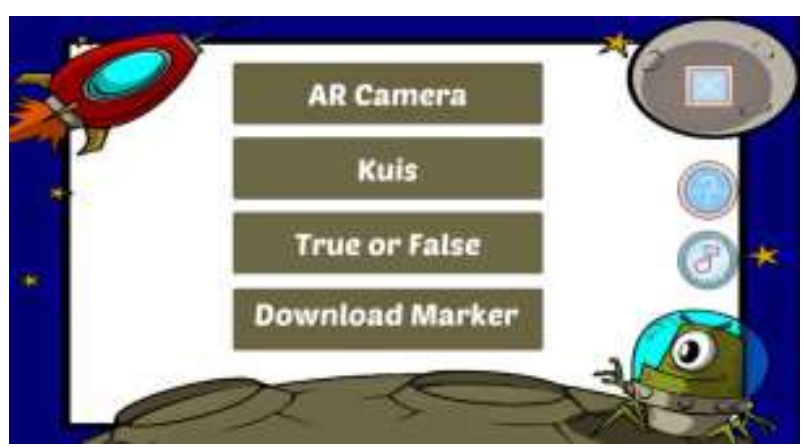

Gambar 3. Tampilan Awal Augmented Reality

Pada gambar 3 adalah tampilan awal aplikasi yang terdapat button AR Camera, Kuis, True or False, Download Marker, informasi cara penggunaan aplikasi, tombol on - off musik, dan close.

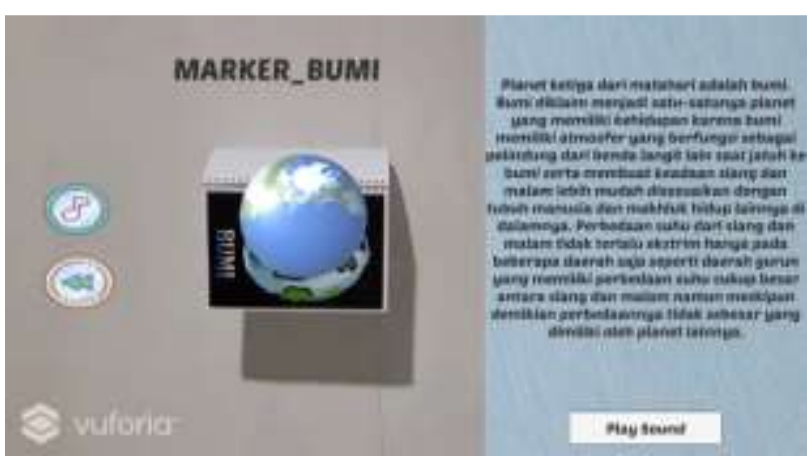

Gambar 4. Scan Marker Bumi

Gambar 4 menunjukan ketika marker bumi di scan menggunakan kamera handphone maka akan muncul objek 3D beserta dengan materi penjelasan dan Button play sound. Selain itu pada menu AR Camera terdapat Button Back dan on - off musik. 
Available Online at https://ejurnal.stmik-budidarma.ac.id/index.php/mib DOI $10.30865 /$ mib.v4i1.1875

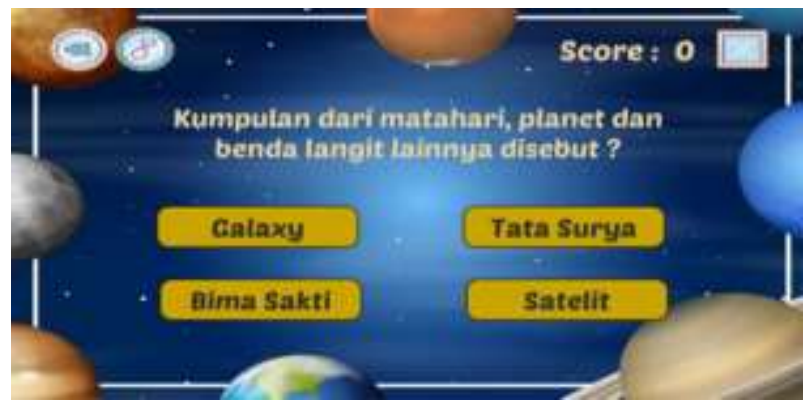

Gambar 5. Tampilan Menu Kuis

Pada gambar 5 adalah menu kuis yang digunakan untuk mengukur seberapa paham siswa terhadap materi yang sudah dipelajari. Kuis terdiri dari soal pilihan ganda 4 pilihan jawaban. Pada menu true or false, terdapat soal dengan pilihan dua jawaban dengan true dan false. Di kanan atas kedua menu ini terdapat score yang diperoleh saat mengerjakan soal, score akan bertambah 10 poin jika berhasil menjawab pertanyaan dengan benar. Pada menu kuis dan true or false juga terdapat button back dan on - off musik, dan close.

Menu download marker digunakan untuk menunjukan marker yang dapat di download melalui google drive untuk dugunakan pada menu AR Camera.

\subsection{Pengujian Gambar Marker}

Pengujian dilakukan dengan menggunakan black box. yang bertujuan menghilangkan dan mengidentifikasi masalah pada aplikasi. Berikut contoh pengujian marker menggunakan black box.

Tabel 1. Tabel Pengujian Gambar Marker

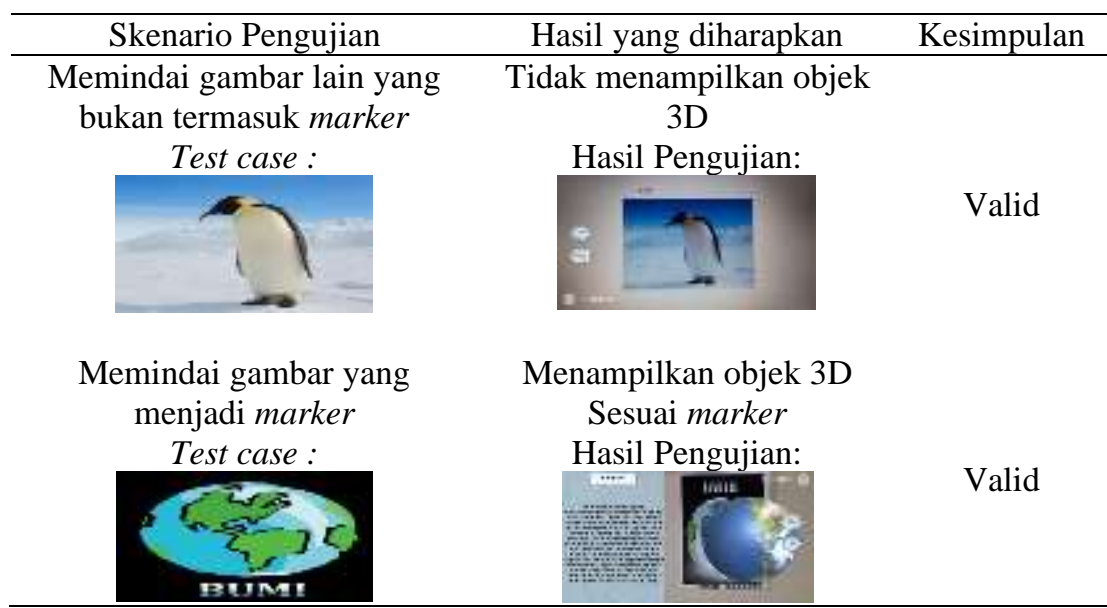

Tabel 1 adalah tabel yang berisikan pengujian salah satu marker yang ada. Hasil yang di dapatkan adalah valid, karena marker yang di scan menampilkan objek 3D yang sesuai. Dari hasil pengujian black box Marker pada tabel 1, maka didapatkan hasil yang tertera pada tabel 2.

Tabel 2. Hasil Pengujian Black Box Marker

\begin{tabular}{ccc}
\hline \multirow{2}{*}{ Objek yang Diuji } & Skenario Pengujian & \multicolumn{2}{c}{ Hasil Pengujian } \\
& Berhasil & Gagal \\
\hline Merkurius & Menunjukan Marker Merkurius & $\checkmark$ \\
Venus & Menunjukan Marker Venus & $\checkmark$ \\
Bumi & Menunjukan Marker Bumi & $\checkmark$ \\
Mars & Menunjukan Marker Mars & $\checkmark$ \\
Jupiter & Menunjukan Marker Jupiter & $\checkmark$ \\
Saturnus & Menunjukan Marker Saturnus & $\checkmark$ \\
Uranus & Menunjukan Marker Uranus & $\checkmark$ \\
Neptunus & Menunjukan Marker Neptunus & $\checkmark$ \\
Matahari & Menunjukan Marker Matahari & $\checkmark$ \\
Bulan & Menunjukan Marker Bulan & $\checkmark$ \\
Asteroid & Menunjukan Marker Asteroid & $\checkmark$ \\
Tata Surya & Menunjukan Marker Tata Surya & $\checkmark$ \\
\hline
\end{tabular}


Available Online at https://ejurnal.stmik-budidarma.ac.id/index.php/mib DOI $10.30865 /$ mib.v4i1.1875

Pada tabel 2 memperlihatkan daftar marker yang ada kemudian di tes menggunakan black box, hasilnya marker yang dipindai berhasil mengelurkan objek 3D yang sesuai.

\subsection{Pengujian Fitur Aplikasi}

Pengujian dilakukan dengan menggunakan black box yang bertujuan untuk menghilangakan dan mengidentifikasi masalah pada aplikasi. Berikut contoh salah satu pengujian fitur aplikasi menggunakan black box.

Tabel 3. Tabel Black Box Pengujian Fitur

\begin{tabular}{ccc}
\hline Skenario Pengujian & Hasil yang diharapkan & Kesimpulan \\
\hline Mengklik button download & $\begin{array}{c}\text { Sistem akan mengarahkan } \\
\text { ke googe drive untuk }\end{array}$ & \\
mendownload marker & \\
Test case : & Hasil Pengujian: & Valid \\
Pengujian button download & & \\
marker & &
\end{tabular}

Tabel 3 adalah tabel yang berisi pengujian salah satu fitur yang ada, yaitu fitur download marker. Hasil yang didapatkan adalah valid, karena dapat membawa ke google drive yang menyimpan marker yang dibutuhkan untuk menu AR Camera. Dari hasil tabel 3, maka didapatkan hasil yang tertera pada tabel 4.

Tabel 4. Hasil Pengujian Black Box fitur aplikasi

\begin{tabular}{ccc}
\hline \multirow{2}{*}{ Fitur yang Diuji } & Skenario Pengujian & \multicolumn{2}{c}{ Hasil Pengujian } \\
& Menghidupkan dan mematikan music & $\checkmark$ \\
Music on-off & Kembali ke halaman sebelum nya & $\checkmark$ \\
Back & Menutup aplikasi pembelajaran & $\checkmark$ \\
Close & Medengarkan penjelasan dari objek 3D & $\checkmark$ \\
Play Sound & $\checkmark$ \\
Download Marker & Mendownload marker yang disediakan & $\checkmark$ \\
\hline
\end{tabular}

Pada tabel 4 memperlihatkan daftar fitur yang ada pada aplikasi, kemudian di tes menggunakan black box. Hasil yang didapatkan adalah semua fitur berhasil berfungsi dengan baik.

\subsection{Pengujian Jarak dan Sudut Marker}

Pengujian dilakukan dengan menggunakan black box. yang bertujuan menghilangkan dan mengidentifikasi masalah pada aplikasi. Berikut contoh salah satu pengujian jarak dan sudut marker menggunakan black box.

Tabel 5. Pengujian Black Box Jarak dan Sudut Marker

\begin{tabular}{ccc}
\hline Skenario Pengujian & Hasil yang diharapkan & Kesimpulan \\
\hline Memindai marker dengan jarak $30 \mathrm{~cm}$ & $\begin{array}{c}\text { Marker dapat dideteksi } \\
\text { Hasil Pengujian: }\end{array}$ & \\
Test case : & & Valid
\end{tabular}

Memindai marker dengan jarak $60 \mathrm{~cm}$

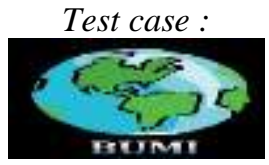

Memindai marker dengan jarak $90 \mathrm{~cm}$ Test case :

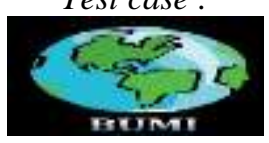

Marker dapat dideteksi

Hasil Pengujian:

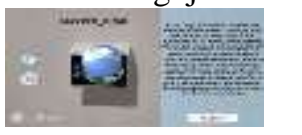

Valid

Marker dapat dideteksi

Hasil Pengujian:

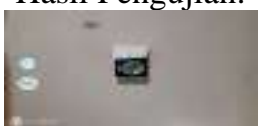

Valid 
Available Online at https://ejurnal.stmik-budidarma.ac.id/index.php/mib DOI 10.30865/mib.v4i1.1875

Memindai marker dengan sudut $0^{\circ}$

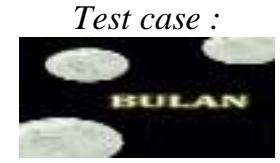

Memindai marker dengan sudut $>45^{\circ}$

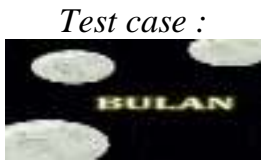

Memindai marker dengan sudut $>90^{\circ}$

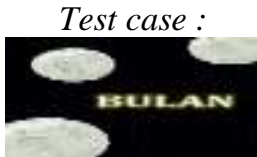

Marker dapat dideteksi

Hasil Pengujian:

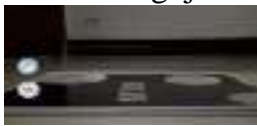

Marker dapat dideteksi Hasil Pengujian:

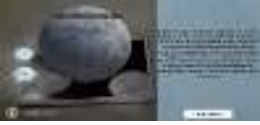

Marker dapat dideteksi

Valid

Invalid

Valid

Hasil Pengujian:

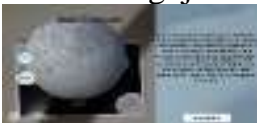

Tabel 5 berisi pengujian jarak dan sudut marker menggunakan marker bumi dan bulan. Hasil yang di dapatkan valid untuk marker yang di pindai pada jarak 30-90 dengan sudut $45^{\circ}-90^{\circ}$. Kemudian pada sudut $0^{\circ}$ hasil yang di dapat adalah invalid. Dari hasil tabel 5, maka didapatkan hasil yang tertera pada tabel 6 dan tabel 7.

Tabel 6. Hasil Pengujian Black Box Jarak Marker

\begin{tabular}{cccc}
\hline Objek yang Diuji & \multicolumn{3}{c}{$\begin{array}{c}\text { Jarak } \\
<60\end{array}$} \\
\hline Merkurius & Terdeteksi & Terdeteksi & Tidak terdeteksi \\
Venus & Terdeteksi & Terdeteksi & Tidak terdeteksi \\
Bumi & Terdeteksi & Terdeteksi & Tidak terdeteksi \\
Mars & Terdeteksi & Terdeteksi & Tidak terdeteksi \\
Jupiter & Terdeteksi & Terdeteksi & Tidak terdeteksi \\
Saturnus & Terdeteksi & Terdeteksi & Tidak terdeteksi \\
Uranus & Terdeteksi & Terdeteksi & Tidak terdeteksi \\
Neptunus & Terdeteksi & Terdeteksi & Tidak terdeteksi \\
Matahari & Terdeteksi & Terdeteksi & Tidak terdeteksi \\
Bulan & Terdeteksi & Terdeteksi & Tidak terdeteksi \\
Asteroid & Terdeteksi & Terdeteksi & Tidak terdeteksi \\
Tata Surya & Terdeteksi & Terdeteksi & Tidak terdeteksi \\
\hline
\end{tabular}

Pada tabel 6 memperlihatkan jarak marker yang dapat di deteksi dari hasil tes menggunakan black box. Hasil yang didapatkan adalah pada jarak 30-90 marker dapat dipindai dengan baik(valid), pada jarak >90 marker sudah tidak dapat terdeteksi (invalid), sehingga tidak memunculkan objek 3D.

Tabel 7. Hasil Pengujian Black Box Jarak Marker

\begin{tabular}{cccc}
\hline Objek yang Diuji & \multicolumn{3}{c}{$\begin{array}{c}\text { Jarak } \\
<60\end{array}$} \\
\hline Merkurius & Terdeteksi & Terdeteksi & Tidak terdeteksi \\
Venus & Terdeteksi & Terdeteksi & Tidak terdeteksi \\
Bumi & Terdeteksi & Terdeteksi & Tidak terdeteksi \\
Mars & Terdeteksi & Terdeteksi & Tidak terdeteksi \\
Jupiter & Terdeteksi & Terdeteksi & Tidak terdeteksi \\
Saturnus & Terdeteksi & Terdeteksi & Tidak terdeteksi \\
Uranus & Terdeteksi & Terdeteksi & Tidak terdeteksi \\
Neptunus & Terdeteksi & Terdeteksi & Tidak terdeteksi \\
Matahari & Terdeteksi & Terdeteksi & Tidak terdeteksi \\
Bulan & Terdeteksi & Terdeteksi & Tidak terdeteksi \\
Asteroid & Terdeteksi & Terdeteksi & Tidak terdeteksi \\
Tata Surya & Terdeteksi & Terdeteksi & Tidak terdeteksi \\
\hline
\end{tabular}

Pada tabel 7 memperlihatkan sudut marker yang dapat di deteksi dari hasil tes menggunakan black box. Hasil yang di dapatkan adalah pada sudut $45^{\circ}-90^{\circ}$ marker dapat dipindai dan memunculkan objek(valid), pada sudut $0^{\circ}$ marker tidak dapat memunculkan objek 3D(invalid).

\subsection{Data Hasil Kuesioner}


JURNAL MEDIA INFORMATIKA BUDIDARMA

Volume 4, Nomor 1, Januari 2020, Page 178-184

ISSN 2614-5278 (media cetak), ISSN 2548-8368 (media online)

Available Online at https://ejurnal.stmik-budidarma.ac.id/index.php/mib

DOI $10.30865 /$ mib.v4i1.1875

Dilakukan survey menggunakan google form untuk mengetahui pendapat responden mengenai aplikasi augmented reality tata surya. Total responden yang di survey adalah 10 orang siswa sekolah dasar.

Tabel 8. Hasil Kuesioner Augmented Reality Tata Surya

\begin{tabular}{cccc}
\hline No & Aspek & Indikator & $\begin{array}{c}\text { Jawaban } \\
\text { Responden }\end{array}$ \\
\hline 1 & Melihat aplikasi augmented reality pelajaran tata & Ya & 10 \\
& surya untuk yang pertama kali? & Tidak & 0 \\
2 & Apakah aplikasi Augmented Reality pelajaran tata & Ya & 10 \\
& surya mudah untuk digunakan? & Tidak & 0 \\
3 & Apakah belajar tata surya menjadi menyenangkan & Ya & 10 \\
& dan memudahkan menerima pelajaran? & Tidak & 0 \\
4 & Menu kuis dan true or false membantu mengukur & Ya & 10 \\
& pemahaman materi? & Tidak & 0 \\
5 & Aplikasi Augmented Reality tata surya dapat & Ya & 10 \\
& dijadikan sebagai media pembelajaran? & Tidak & 0 \\
\hline
\end{tabular}

Didapatkan hasil dari tabel 8 yaitu, dari 10 responden menjawab "Ya" pada semua pertanyaan yang diajukan, sehingga perhitungan persentase[11] setiap pertanyaan adalah :

$\mathrm{P}=\mathrm{Nt} / \mathrm{N} \times 100 \%$

$\mathrm{P}=10 / 10 \times 100 \%$

$\mathrm{P}=100 \%$

Dimana :

$\mathrm{P}=$ Persentase jawaban

$\mathrm{Nt}=$ Jumlah jawaban responden

$\mathrm{N}$ = Jumlah seluruh Responden

\section{KESIMPULAN}

Berdasarkan hasil penelitian dan kuesioner dari 10 responden, maka dapat disimpulkan bahwa media pembelajaran tata surya berbasis augmented reality dengan metode marker based tracking dapat digunakan sebagai media pembelajaran untuk siswa sekolah dasar sehingga belajar lebih menyenangkan. AR camera dapat berjalan dengan baik jika marker dipindai pada jarak $30-80 \mathrm{~cm}$ dan sudut $45^{\circ}-90^{\circ}$. Fitur-fitur yang ada pada aplikasi ini juga dapat berfungsi dengan baik. Menu kuis dan true or false telah dibuat untuk mengukur pemahaman materi para siswa.

\section{REFERENCES}

[1] A. Fitriansyah, "Penggunaan Teknologi Augmented Reality Dalam Mempelajari Sistem Tata Surya dengan Android," Fakt. Exacta, vol. 11, no. 2, p. 179, 2018.

[2] D. Rohendi, S. Septian, and H. Sutarno, "The Use of Geometry Learning Media Based on Augmented Reality for Junior High School Students," IOP Conf. Ser. Mater. Sci. Eng., vol. 306, no. 1, 2018.

[3] C. A. Sugianto, "Aplikasi Edukasi Tata Surya Menggunakan Augmented Reality Berbasis Mobile," no. June 2018, pp. 30-39, 2015

[4] P. R. Aryani, I. Akhlis, and B. Subali, "Penerapan Model Pembelajaran Inkuiri Terbimbing Berbentuk Augmented Reality pada Peserta Didik untuk Meningkatkan Minat dan Pemahaman Konsep IPA," Unnes Phys. Educ. J. Terakreditasi SINTA, vol. 8, no. 2, pp. 1-12, 2019.

[5] D. Atmajaya, "Implementasi Augmented Reality untuk Pembelajaran Interaktif," J. Ilm. Ilk. UMI Makassar, vol. 9, pp. 227-232, 2017.

[6] F. Ozdamli and D. Karagozlu, "Preschool teachers' opinions on the use of augmented reality application in preschool science education," Croat. J. Educ., vol. 20, no. 1, pp. 43-74, 2018.

[7] V. Kasinathan, A. Mustapha, M. A. Hasibuan, and A. Z. Z. Abidin, "First Discovery: Augmented Reality for learning solar systems," Int. J. Integr. Eng., vol. 10, no. 6, pp. 148-154, 2018.

[8] B. Satria and Prihandoko, "Implementasi Metode Marker Based Tracking Pada Aplikasi Bangun," Univ. AMIKOM Yogyakarta, pp. 1-5, 2018.

[9] E. Cieza and D. Lujan, "Educational Mobile Application of Augmented Reality Based on Markers to Improve the Learning of Vowel Usage and Numbers for Children of a Kindergarten in Trujillo," Procedia Comput. Sci., vol. 130, pp. 352-358, 2018.

[10] R. Andrea, S. Lailiyah, F. Agus, and Ramadiani, “"Magic Boosed' an elementary school geometry textbook with markerbased augmented reality," Telkomnika (Telecommunication Comput. Electron. Control., vol. 17, no. 3, pp. 1242-1249, 2019.

[11] R. M. Indrawati, "Peningkatan Aktivitas Dan Hasil Belajar Materi Peristiwa Sekitar Proklamasi Melalui Bermain Peran," J. Elem. Educ., vol. 2, no. 1, pp. 15-22, 2013. 